\title{
Chromatographic Optical Resolution of Enantiomers on Polyamides Containing 1,2-Disubstituted Cyclohexane Moiety as a Chiral Residue
}

\author{
Yoshio Oкамото, ${ }^{*}$ Yoshikazu Nagamura, Toru Fukumoto, \\ and Koichi Hatada \\ Department of Chemistry, Faculty of Engineering Science, Osaka University, \\ Toyonaka, Osaka 560, Japan
}

(Received March 8, 1991)

\begin{abstract}
Optically active polyamides having (-)-1,2-trans-diaminocyclohexane [( - )-DA] or $(+)$-1,2-trans-cyclohexane dicarboxylic acid $[(+)$-CDA] residue in main chain were synthesized by polycondensation. Polyamides with a $p$-phenylene group in main chain showed better resolution for several racemic compounds than the polyamides with a polymethylene group $\left[\left(\mathrm{CH}_{2}\right)_{n}\right.$ $(n=2-7)]$ in main chain. Among the polyamides with a polymethylene group in main chain, the polyamides with a shorter polymethylene group showed better chiral recognition abilities than the polyamides with a longer polymethylene group. Polyamides derived from (-)-trans-3,6endomethylene-1,2,3,6-tetrahydrophtharic acid [(-)-ETHF] showed low chiral recognition ability. CD spectra of these polyamides showed characteristic patterns. Odd-even effect was observed in $\mathrm{CD}$ spectra of the polyamides having a series of a polymethylene group.
\end{abstract}

KEY WORDS Chromatography / Optical Resolution / 1,2-Diaminocyclohexane / 1,2-Cyclohexane Dicarboxylic Acid / Optically Active Polyamide / Chiral Stationary Phase /

Optical resolution by high-performance liquid chromatography (HPLC) has already become an important, practically useful method for the separation of optical isomers, and various optically active polymers have been tested as chiral stationary phases (CSP). ${ }^{1,2}$ The polymers include several synthetic ones such as polyacrylamides, ${ }^{3}$ polymethacrylamides, ${ }^{4}$ polymethacrylates, ${ }^{5}$ poly $(\alpha$-amino acid $),{ }^{6}$ polysulfoxide, ${ }^{7}$ poly(crown ether), ${ }^{8}$ and polyamides $^{9-11}$ in addition to naturally occurring macromolecules, proteins and polysaccharides. Saigo, Hasegawa, and coworkers reported that polyamides containing a cyclobutane ring 9,10 and a polyamide derived from 1,2-diphenylethylenediamine ${ }^{11}$ show characteristic optical resolving abilities. On the other hand, Over- berger et al. investigated extensively on the syntheses and conformation of optically active polyamides containing cyclic moieties such as cyclohexane, ${ }^{12}$ cyclobutane, and cyclopropane in main chains. ${ }^{13,14}$ However, no data are available on the optical resolving abilities of these polyamides.

In this paper, we wish to report the chiral recognition abilities as CSP and CD spectra of a series of optical active polyamides having a cyclohexane moiety in main chain.

\section{EXPERIMENTAL}

\section{Materials}

$(1 R, 2 R)-(-)$-1,2-trans-Diaminocyclohexane $[(-)-\mathrm{DA}]\left([\alpha]_{\mathrm{D}}^{20}-33.4^{\circ} \quad\left(c=1.0 \mathrm{~g} \mathrm{dl}^{-1}\right.\right.$ in

* Present address: Department of Applied Chemistry, Faculty of Engineering, Nagoya University, Chikusa-ku, Nagoya 464-01, Japan. 
$\left.\mathrm{H}_{2} \mathrm{O}\right)$ ), which was kindly supplied by Toray, was purified by distillation under reduced pressure before polymerization. $(1 S, 2 S)-(+)-$ And $(1 R, 2 R)-(-)$-trans-1,2-cyclohexanedicarboxylic acids $[(+)$ and (-)-CDA] were obtained by optical resolution of racemic acid (Nakarai tesque) with quinine. ${ }^{15}$ Quinine salt was recrystallized from $95 \%$ ethanol. Free $(+)$-diacid isolated from the quinine salt was recrystallized from water again $(\mathrm{mp} 180$ $180.5^{\circ} \mathrm{C}$ (lit., $\left.{ }^{16} \mathrm{mp} 179.5-181.5^{\circ} \mathrm{C}\right),[\alpha]_{\mathrm{D}}^{20}$ $+19.4^{\circ}\left(c=1.0 \mathrm{~g} \mathrm{dl}^{-1}\right.$ in acetone $)$. Enantiomeric excess of the acid was found to be greater than $99.5 \%$ by HPLC analysis using a cellulose tris(3,5-dimethylphenylcarbamate) column. ${ }^{17}$ The (-)-diacid recovered from the mother liquor of the recrystallization of the quinine salt was also recrystallized from water $(\mathrm{mp}$ $176-178^{\circ} \mathrm{C}$ (lit., $\left.{ }^{16} \mathrm{mp} 175-180^{\circ} \mathrm{C}\right),[\alpha]_{\mathrm{D}}^{20}$ $-18.6^{\circ}\left(c=1.0 \mathrm{~g} \mathrm{dl}^{-1}\right.$ in acetone $)$.

( \pm )-trans-3,6-Endomethylene-1,2,3,6-tetrahydrophthaloyl diphenyl ester was prepared by esterification of $( \pm)$-trans-3,6-endomethylene1,2,3,6-tetrahydrophthaloyl dichloride (Aldrich). Racemic diester was preparatively resolved on an HPLC column $(50 \times 2$ (i.d.) $\mathrm{cm})$ packed with amylose tris(3,5-dimethylphenylcarbamate) using hexane-2-propanol $(80: 20)$ as an eluent. ${ }^{17}$ About $50 \mathrm{mg}$ of the racemic diester was completely resolved in one injection. (-)-Diester isolated as the first fraction was hydrolyzed to give (-)-diacid ((-)ETHF). Its optical purity was nearly $100 \%$ by chiral HPLC analysis.

Diacid chlorides of (+)- and (-)-CDA, $\alpha, \omega$-alkanedicarboxylic acid $\left[\mathrm{HO}_{2} \mathrm{C}-\left(\mathrm{CH}_{2}\right)_{n}\right.$ $\left.\mathrm{CO}_{2} \mathrm{H}, n=3,5\right]$, and (-)-ETHF were prepared by treating the acids with an excess of purified thionyl chloride and were purified by distillation. Terephthaloyl acid dichloride and $\alpha, \omega$ alkanedicarboxylic acid dichlorides $(n=2,4,7$, and 8) (Nakarai and Wako) were purified by distillation under reduced pressure. Suberoyl chloride ( $n=6$, Aldrich) was used without further purification.

$\alpha, \omega$-Alkanediamines $\left[\mathrm{H}_{2} \mathrm{~N}-\left(\mathrm{CH}_{2}\right)_{n} \mathrm{NH}_{2}, n=\right.$
2-6] (Nakarai tesque) were purified by distillation under reduced pressure just before polymerization. $p$-Phenylenediamine was recrystallized from ethyl acetate.

Triethylamine $\left(\mathrm{Et}_{3} \mathrm{~N}\right)$ was distilled and then stored on $\mathrm{NaOH}$ pellets. $N, N$-Dimethylacetamide (DMA) was distilled under reduced pressure and then stored on Molecular Sieves $4 \mathrm{~A}$.

\section{Synthesis of Polyamides 1-14}

Polyamides 1-14 were synthesized by polycondensation in solution. Under nitrogen atmosphere, a diamine ( $c a .1 \mathrm{~g}$ ) and lithium chloride $(2 \mathrm{~g})$ were placed in a $50 \mathrm{ml}$ two-necked flask, and then DMA (40 ml) and $\mathrm{Et}_{3} \mathrm{~N}(2 \mathrm{ml})$ were added with syringes. To the above mixture cooled to $0^{\circ} \mathrm{C}$, a diacid chloride was added dropwise under vigorous stirring. After 1$20 \mathrm{~h}$, the reaction mixture was poured into $400 \mathrm{ml}$ of water to precipitate a polyamide which was collected by centrifugation. The

Table I. Syntheses of polyamides $\mathbf{1}-\mathbf{1 4}$

\begin{tabular}{|c|c|c|c|}
\hline \multirow{2}{*}{ Polyamide } & Yield & {$[\alpha]_{\mathrm{D}}^{\mathrm{a}}$} & {$[\eta]^{\mathrm{b}}$} \\
\hline & $\%$ & deg & $10^{2} \mathrm{~cm}^{3} \mathrm{~g}^{-1}$ \\
\hline 1 & 90 & -211 & 0.21 \\
\hline 2 & 46 & +65.4 & - \\
\hline 3 & 64 & +73.6 & 0.10 \\
\hline 4 & 89 & +66.1 & 0.17 \\
\hline 5 & 100 & +64.1 & 0.20 \\
\hline 6 & 94 & +51.0 & 0.14 \\
\hline 7 & 79 & +53.0 & 0.14 \\
\hline 8 & 97 & +239 & 0.16 \\
\hline 9 & 57 & +56.5 & 0.12 \\
\hline 10 & $67(82)^{\mathrm{c}}$ & $+57.5(-67.1)^{\mathrm{c}}$ & 0.13 \\
\hline 11 & 70 & +68.5 & 0.15 \\
\hline 12 & $81(83)^{\mathrm{c}}$ & $+30.6(-32.7)^{c}$ & 0.13 \\
\hline 13 & 100 & +45.4 & 0.13 \\
\hline 14 & 72 & $-220^{\mathrm{d}}$ & $0.17^{\mathrm{d}}$ \\
\hline
\end{tabular}

a In dichloroạcetic acid, $1.0 \mathrm{~g} \mathrm{dl}^{-1}$ at $25^{\circ} \mathrm{C}$.

b In dichloroacetic acid at $30^{\circ} \mathrm{C}$.

c Values in parentheses are the yields of polyamides obtained from (-)-CDA.

d In dimethyl sulfoxide. 
Optical Resolution on Polyamides

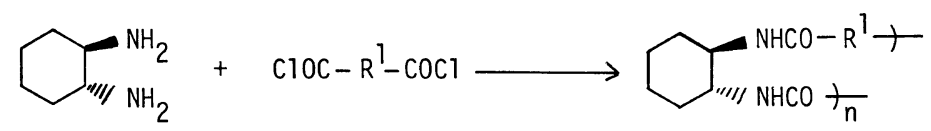

Polyamide $1 \sim 7$

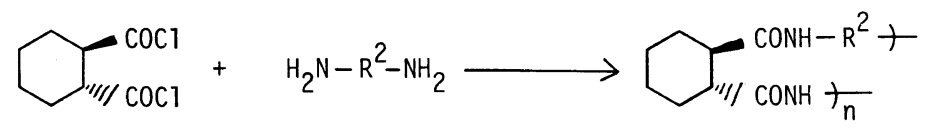

Polyamide $8 \sim 13$
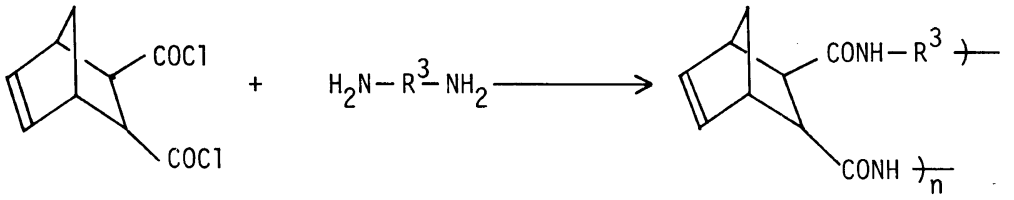

Polyamide 14

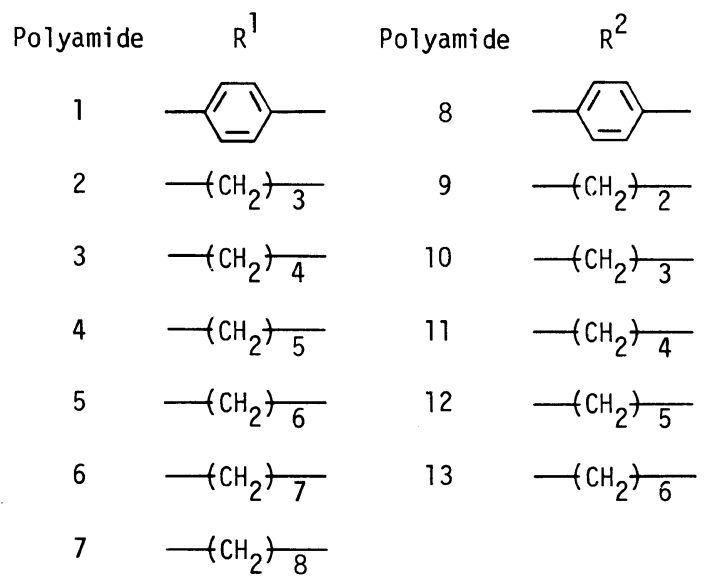

Polyamide $\quad \mathrm{R}^{3}$

14

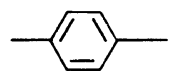

Scheme 1.

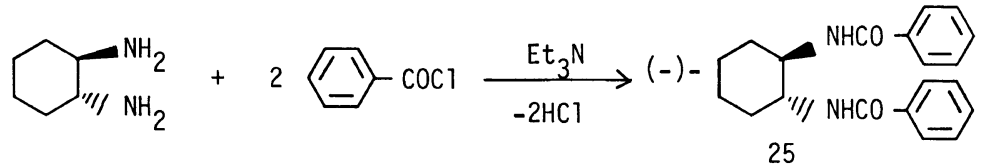

25
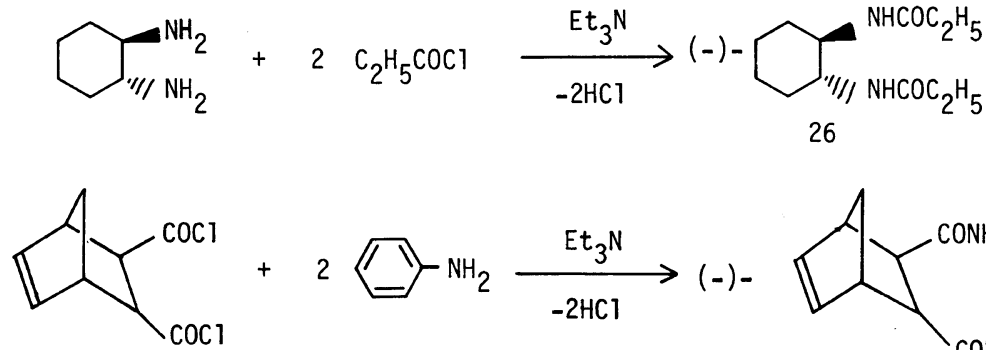

Scheme 2.

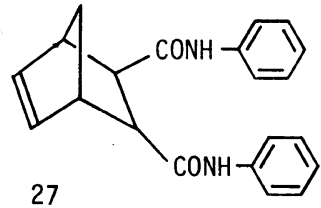


polyamide was washed with water and methanol. The polyamide thus obtained was dried in vacuo at $50^{\circ} \mathrm{C}$ for $3 \mathrm{~h}$.

Table I shows the results of the syntheses of polyamides $1-14$.

Synthesis of Model Compounds 25, 26, and 27

Model compounds 25, 26, and 27 were synthesized in a similar manner as described in the polymerization procedure.

An acid chloride was added to a benzene solution of an amine. Precipitated amide was separated by filtration, washed with water, ethanol, and ether, and then dried in vacuo. All model compounds showed reasonable IR and ${ }^{1} \mathrm{H}$ NMR spectra. Model Compound 25: Yield, $52 \%$; mp $254-255^{\circ} \mathrm{C}$. Anal. Calcd for $\mathrm{C}_{20} \mathrm{H}_{22} \mathrm{O}_{2} \mathrm{~N}_{2}$ : C, $74.51 \% ; \mathrm{H}, 6.88 \% ; \mathrm{N}$, $8.69 \%$. Found: C, 74.42\%; H, 6.90\%; N, $8.62 \%$. IR (Nujol): $v 1635 \mathrm{~cm}^{-1} \quad(\mathrm{C}=\mathrm{O})$. Model Compound 26: Yield, 17\%; mp 245.5$256.5^{\circ}$ C. Anal. Calcd for $\mathrm{C}_{12} \mathrm{H}_{20} \mathrm{O}_{2} \mathrm{~N}_{2}$ : C, $63.69 \%$; H, 9.80\%; N, 12.38\%. Found: C, $63.57 \%$; H, 9.76\%; N, $12.27 \%$. IR (Nujol): $v$ $1638 \mathrm{~cm}^{-1} \quad(\mathrm{C}=\mathrm{O})$. Model Compound 27: Yield, $98 \%$; mp $301-302^{\circ} \mathrm{C}$. Anal. Calcd for $\mathrm{C}_{21} \mathrm{H}_{20} \mathrm{O}_{2} \mathrm{~N}_{2}$ : C, 75.88\%; $\mathrm{H}, 6.60 \% ; \mathrm{N}$, $8.43 \%$. Found: C, $75.83 \%$; H, $6.10 \%$; N, $8.56 \%$. IR (Nujol): $v 1651 \mathrm{~cm}^{-1}(\mathrm{C}=\mathrm{O})$.

\section{Preparation of Chiral Stationary Phase}

Macroporous silica gel (Macherey-Nagel, NUCLEOSIL 4000-7) was treated with 3aminopropyltriethoxysilane in benzene at $80^{\circ} \mathrm{C}$. Analysis for the silanized silica gel: C, $0.43 \% ; \mathrm{H}, 0.15 \%$. A polyamide $(0.68 \mathrm{~g})$ was dissolved in $8 \mathrm{ml}$ of a solvent $(1,1,1,3,3,3$ hexafluoro-2-propanol or trifluoroacetic acid (TFA)). The solution ( $c a .4 \mathrm{ml}$ ) was added to the above silanized macroporous silica gel $(3 \mathrm{~g})$, and the wetted silica gel was dried under vacuum. This coating process was repeated with the remaining solution. The packing materials thus obtained were packed in a stainless steel tube $(250 \times 4.6($ i.d. $) \mathrm{mm})$ at $380 \mathrm{~kg} \mathrm{~cm}^{-2}$ by a slurry method. The plate numbers of these columns were $2500-3500$ for 1,3,5-tri-tert-butylbenzene with hexane $(0.5 \mathrm{ml}$ $\left.\mathrm{min}^{-1}\right)$ as an eluent at $25^{\circ} \mathrm{C}$. Dead time $\left(t_{0}\right)$ of the column was also estimated with 1,3,5-tritert-butylbenzene. ${ }^{18}$

\section{Measurement}

A JASCO TRIROTAR-II chromatograph equipped with UV (JASCO UVIDEC-100-III) and polarimetric (JASCO DIP-181C) detectors were used. Optical rotation was monitored in a flow cell $(50 \times 2$ (i.d.)mm) at full lamp (mercury) intensity without a filter. Resolution on an analytical column $(25 \times 0.46$ (i.d.) $\mathrm{cm}$ ) was carried out with a hexane-2propanol $(90: 10$ or $95: 5)$ mixture at a flow-rate of $0.5 \mathrm{ml} \mathrm{min}^{-1}$ at $25^{\circ} \mathrm{C}$ unless otherwise stated. IR spectra were taken on a JASCO IR-810 spectrophotometer in Nujol. $\mathrm{CD}$ and UV spectra were measured on a JASCO J-500 spectropolarimeter and on a JASCO UVIDEC-610C spectrophotometer, respectively, at room temperature. $\mathrm{CD}$ and $\mathrm{UV}$ spectra of films were measured in the same manner as reported by Chen et al. ${ }^{10}$ The films were prepared by casting their solution $\left(20-30 \mathrm{mg} \mathrm{ml}^{-1}\right.$ in TFA) on the surface of a quartz plate. Each $\mathrm{CD}$ spectrum was measured four times by rotating the sample quartz plate by 45,90 , and $120^{\circ}$ from the first position around the axis of the incident light beam. Every spectrum gave almost identical patterns. The CD spectra were calibrated to the same molecular concentration on the basis of the data of UV measurement.

\section{RESULTS AND DISCUSSION}

The resolution of racemic Tröger base $\mathbf{1 5}$ on optical active polyamide $\mathbf{1}$ is shown in Figure 1. The enantiomers were completely separated eluting at $t_{1}$ and $t_{2}$. Capacity factors $k_{1}^{\prime}$ and $k_{2}^{\prime}$, which are estimated as $\left(t_{1}-t_{0}\right) / t_{0}$ and $\left(t_{2}-t_{0}\right) / t_{0}$, are 0.33 and 1.28 , respectively. Separation factor, $\alpha=k_{2}^{\prime} / k_{1}^{\prime}$, and resolution factor, $R_{\mathrm{s}}=2\left(t_{2}-t_{1}\right) /\left(w_{1}+w_{2}\right)$, are found to be 


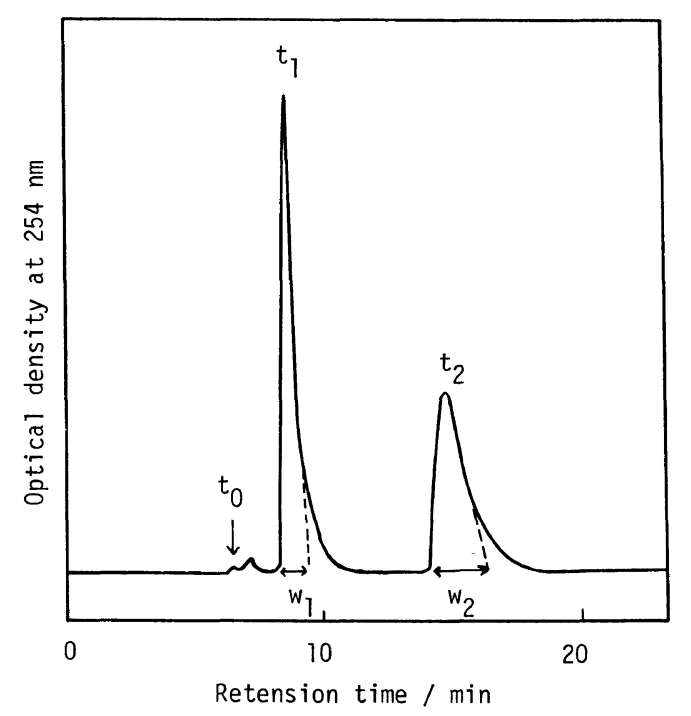

Figure 1. Chromatographic resolution of Tröger base $\mathbf{1 5}$ on polyamide $\mathbf{1}$.

\subsection{4 and 5.12, respectively.}

Table II shows the results of optical resolution of 15, cobalt(III) tris(acetylacetonate) 16, flavanone 17, trans-cyclopropanedicarboxylic acid dianilide 18, 2,2'-dihydroxy6,6'-dimethylbiphenyl 19, 1-(9-anthryl)-2,2,2trifluoroethanol 20, 1,2,2,2-tetraphenylethanol 21, and benzoin 22 on polyamides $1,3,8, \mathbf{1 1}$, and 14. Each polyamide has characteristic chiral recognition ability for the racemic compounds. Among the polyamides having cyclohexane ring, $\mathbf{1}$ and $\mathbf{8}$ with $p$-phenylene groups showed noticeable chiral recognition abilities. Tröger base $\mathbf{1 5}$ was efficiently resolved only by polyamide 1 , and $\mathbf{1 6}$ was resolved by polyamide $\mathbf{8}$ with a very high separation factor $(\alpha=9.27)$. Racemates 19 and 20 were better resolved on polyamides $\mathbf{3}$ and $\mathbf{1 1}$ with tetramethylene groups. These results indicate

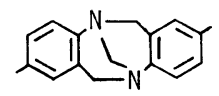

15

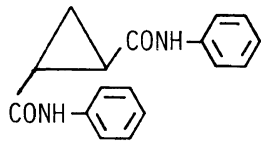

18<smiles>OC(c1ccccc1)C(c1ccccc1)(c1ccccc1)c1ccccc1</smiles>

21

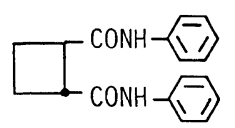

24<smiles></smiles>

16

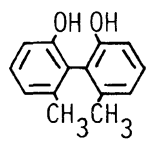

19

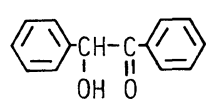

22<smiles>O=C1CC(c2ccccc2)Oc2ccccc21</smiles>

17<smiles>OC(c1ccccc1-c1ccccc1)C(F)(F)F</smiles>

20<smiles>Oc1ccc2cccc3c4cccc5cccc(c1c23)c54</smiles>

23

Scheme 3. 
Table II. Resolution of enantiomers 15-21 on polyamides $1,3,8,11$, and $14^{\mathrm{a}}$

\begin{tabular}{|c|c|c|c|c|c|c|c|c|c|}
\hline \multirow{2}{*}{ Polyamide } & \multicolumn{3}{|c|}{15} & \multicolumn{3}{|c|}{16} & \multicolumn{3}{|c|}{17} \\
\hline & $k_{1}^{\prime}$ & $\alpha$ & $R_{\mathrm{s}}$ & $k_{1}^{\prime}$ & $\alpha$ & $R_{\mathrm{s}}$ & $k_{1}^{\prime}$ & $\alpha$ & $R_{\mathrm{s}}$ \\
\hline 1 & $0.33(+)$ & 3.94 & 5.12 & $1.15(+)$ & $2.29^{b}$ & & $0.82(+)$ & 1.49 & 2.19 \\
\hline 3 & 0.12 & 1.00 & & $0.21(+)$ & 1 & & 0.25 & 1.00 & \\
\hline 8 & $0.72(+)$ & 1 & & $1.14(-)$ & 9.27 & $2.38^{\mathrm{b}}$ & $0.72(+)$ & 1.09 & \\
\hline 11 & $0.10(+)$ & 1 & & $0.20(+)$ & 1 & & 0.18 & 1.00 & \\
\hline 14 & $0.84(+)$ & 1.12 & & 2.92 & 1.00 & & 2.46 & 1.00 & \\
\hline \multirow{2}{*}{ Polyamide } & \multicolumn{3}{|c|}{18} & \multicolumn{3}{|c|}{19} & \multicolumn{3}{|c|}{20} \\
\hline & $k_{1}^{\prime}$ & $\alpha$ & $R_{\mathrm{s}}$ & $k_{1}^{\prime}$ & $\alpha$ & $R_{\mathrm{s}}$ & $k_{1}^{\prime}$ & $\alpha$ & $R_{\mathrm{s}}$ \\
\hline 1 & 0.67 & 1.00 & & $2.80(-)$ & 1.08 & & $1.74(-)$ & 1.07 & \\
\hline 3 & $1.33(+)$ & 1.46 & 0.85 & $3.81(-)$ & 1.27 & 1.03 & $2.65(+)$ & 1.23 & 1.23 \\
\hline 8 & $1.81(+)$ & 1.32 & 0.64 & $4.05(-)$ & $1.05^{\mathrm{b}}$ & & $2.22(+)$ & 1 & \\
\hline 11 & $1.32(+)$ & 1.14 & & $2.82(-)$ & 1.41 & & $2.01(+)$ & 1.15 & 0.63 \\
\hline \multirow[t]{2}{*}{14} & 4.19 & 1.00 & & $2.87(+)$ & 1.20 & 0.47 & $2.70(-)$ & 1 & \\
\hline & \multicolumn{3}{|c|}{21} & \multicolumn{3}{|c|}{$22^{\mathrm{c}}$} & & & \\
\hline & $k_{1}^{\prime}$ & $\alpha$ & $R_{\mathrm{s}}$ & $k_{1}^{\prime}$ & $\alpha$ & $R_{\mathrm{s}}$ & & & \\
\hline 1 & $1.80(+)$ & 1.11 & & 1.47 & 1.00 & & & & \\
\hline 3 & $0.82(+)$ & 1 & & $0.88(+)$ & 1 & & & & \\
\hline 8 & $1.32(-)$ & 1.22 & 0.73 & $1.16(-)$ & $1.12^{\mathrm{b}}$ & & & & \\
\hline 11 & $0.63(-)$ & 1 & & $0.73(+)$ & 1 & & & & \\
\hline 14 & $1.53(+)$ & 1 & & $4.74(+)$ & 1 & & & & \\
\hline
\end{tabular}

a Eluent: hexane-2-propanol $(90: 10)$.

b Eluent: hexane-2-propanol- $\mathrm{CHCl}_{3}(85: 5: 10)$.

c The optical rotation was measured at $435 \mathrm{~nm}$.

that achiral units in the polyamides greatly influence optical resolving abilities. Polyamide 14 with bicyclo ring showed low chiral recognition ability, although it strongly retained several compounds, for instance $\mathbf{1 8}$ and 22.

Tables III and IV show the results of optical resolution of $18,19,20,2,2^{\prime}$-dihydroxy-1,1'binaphthyl 23, and 1,2-trans-cyclobutane dicarboxylic acid dianilide 24 on polyamides 2-7 and 9-13 having different number of methylene groups in main chains. Racemates 15-17, 21, and 22 were not resolved on these polyamides. The chiral recognition abilities of these polyamides depended on the methylene number. For instance, diamide 18 was best resolved on polyamides 5 with a hexamethylene group among the polyamide derived from (-)-DA (Table III). Polyamide 7 bearing an octamethylene group showed almost no chiral recognition ability. In the polyamides derived from (+)-CDA, 13 exhibited exceptionally high chiral discrimination for 24 (Table IV). In the present chromatographic separation, hydrogen bond may be the main interaction between the amide groups of the polyamides and the solutes. This interaction seems to play the most important role for chiral discrimination. Therefore, the compounds bearing a polar group such as hydroxy, amide, and carbonyl groups which can interact through hydrogen bond with the amide groups appear to be 


\section{Optical Resolution on Polyamides}

Table III. Resolution of enantiomers $18-20,23$, and 24 on polyamides $2-7^{\text {a }}$

\begin{tabular}{|c|c|c|c|c|c|c|c|c|c|}
\hline \multirow{2}{*}{ Polyamide } & \multicolumn{3}{|c|}{18} & \multicolumn{3}{|c|}{19} & \multicolumn{3}{|c|}{20} \\
\hline & $k_{1}^{\prime}$ & $\alpha$ & $R_{\mathrm{s}}$ & $k_{1}^{\prime}$ & $\alpha$ & $R_{\mathrm{s}}$ & $k_{1}^{\prime}$ & $\alpha$ & $R_{\mathrm{s}}$ \\
\hline 2 & $2.27(+)$ & 1.26 & 0.60 & $4.63(-)$ & 1.36 & 0.95 & 1.10 & 1.00 & \\
\hline 3 & $2.83(+)$ & 1.39 & 0.85 & $8.84(-)$ & 1.27 & & $4.31(+)$ & 1.21 & \\
\hline 4 & $1.80(+)$ & 1.38 & 1.28 & $2.58(-)$ & 2.13 & 2.13 & 3.15 & 1.06 & \\
\hline 5 & 2.20 & 1.60 & & $3.31(-)$ & 1.29 & & $2.60(+)$ & 1 & \\
\hline 6 & $1.35(+)$ & 1.21 & & $1.38(-)$ & 1.17 & & 2.37 & 1.00 & \\
\hline \multirow[t]{2}{*}{7} & 0.67 & 1.00 & & $0.67(-)$ & 1 & & 1.43 & 1.00 & \\
\hline & \multicolumn{3}{|c|}{23} & \multicolumn{3}{|c|}{24} & & & \\
\hline Polyamide & $k_{1}^{\prime}$ & $\alpha$ & $R_{\mathrm{s}}$ & $k_{1}^{\prime}$ & $\alpha$ & $R_{\mathrm{s}}$ & & & \\
\hline 2 & $11.38(-)$ & 1.42 & 1.40 & $1.05(+)$ & 1.14 & 0.60 & & & \\
\hline 3 & $21.97(-)$ & 1.38 & 1.08 & $1.59(+)$ & 1.21 & 0.60 & & & \\
\hline 4 & $16.89(-)$ & 1.57 & 1.89 & $3.09(+)$ & 1 & & & & \\
\hline 5 & $6.91(-)$ & 1.47 & & $1.36(+)$ & 1.10 & & & & \\
\hline 6 & $7.07(-)$ & 1.32 & 1.26 & $1.14(+)$ & 1.18 & 0.63 & & & \\
\hline 7 & $7.05(-)$ & 1 & & $0.99(+)$ & 1 & & & & \\
\hline
\end{tabular}

a Eluent: hexane-2-propanol $(95: 5)$.

Table IV. Resolution of enantiomers 18-20, 23, and 24 on polyamides $9-13^{\mathrm{a}}$

\begin{tabular}{|c|c|c|c|c|c|c|c|c|c|}
\hline \multirow{2}{*}{ Polyamide } & \multicolumn{3}{|c|}{18} & \multicolumn{3}{|c|}{19} & \multicolumn{3}{|c|}{20} \\
\hline & $k_{1}^{\prime}$ & $\alpha$ & $R_{\mathrm{s}}$ & $k_{1}^{\prime}$ & $\alpha$ & $R_{\mathrm{s}}$ & $k_{1}^{\prime}$ & $\alpha$ & $R_{\mathrm{s}}$ \\
\hline 9 & 0.88 & 1.29 & & $2.01(-)$ & 1.30 & 0.93 & $2.02(+)$ & 1 & \\
\hline $10^{\mathrm{b}}$ & $0.67(-)$ & 1.17 & & $1.47(+)$ & 1.92 & 1.04 & 1.39 & 1.00 & \\
\hline 11 & $1.32(+)$ & 1.14 & & $2.82(-)$ & 1.41 & 1.82 & 2.01 & 1.15 & \\
\hline $12^{\mathrm{b}}$ & $0.70(-)$ & 1.00 & & $1.32(+)$ & 1.43 & 1.03 & 1.66 & 1.00 & \\
\hline \multirow[t]{2}{*}{13} & $1.48(-)$ & 1.16 & & $2.42(-)$ & 1.16 & 0.89 & $2.36(+)$ & 1 & \\
\hline & \multicolumn{3}{|c|}{23} & \multicolumn{3}{|c|}{24} & & & \\
\hline Polyamide & $k_{1}^{\prime}$ & $\alpha$ & $R_{\mathrm{s}}$ & $k_{1}^{\prime}$ & $\alpha$ & $R_{\mathrm{s}}$ & & & \\
\hline 9 & $3.23(-)$ & 2.02 & 1.07 & 0.31 & 1 & & & & \\
\hline $10^{\mathrm{b}}$ & $2.62(+)$ & 2.01 & 1.04 & $0.41(+)$ & 1 & & & & \\
\hline 11 & $5.40(-)$ & 1.52 & & 0.79 & 1.00 & & & & \\
\hline $12^{b}$ & $2.56(+)$ & 1.73 & 1.27 & $0.39(+)$ & 1 & & & & \\
\hline 13 & $6.29(-)$ & 1.32 & 1.28 & $0.46(-)$ & 1.74 & 1.58 & & & \\
\hline
\end{tabular}

a Eluent: hexane-2-propanol $(90: 10)$.

b $(-)$-Diacid was used.

suitable for efficient optical resolution.

Since the polyamides used here were insoluble in a hexane-2-propanol $(90: 10)$ mixture, the chiral HPLC columns were quite stable as far as the mixture was used as an eluent.

The fact that chiral discrimination of CSP depended on the number of the methylene units 


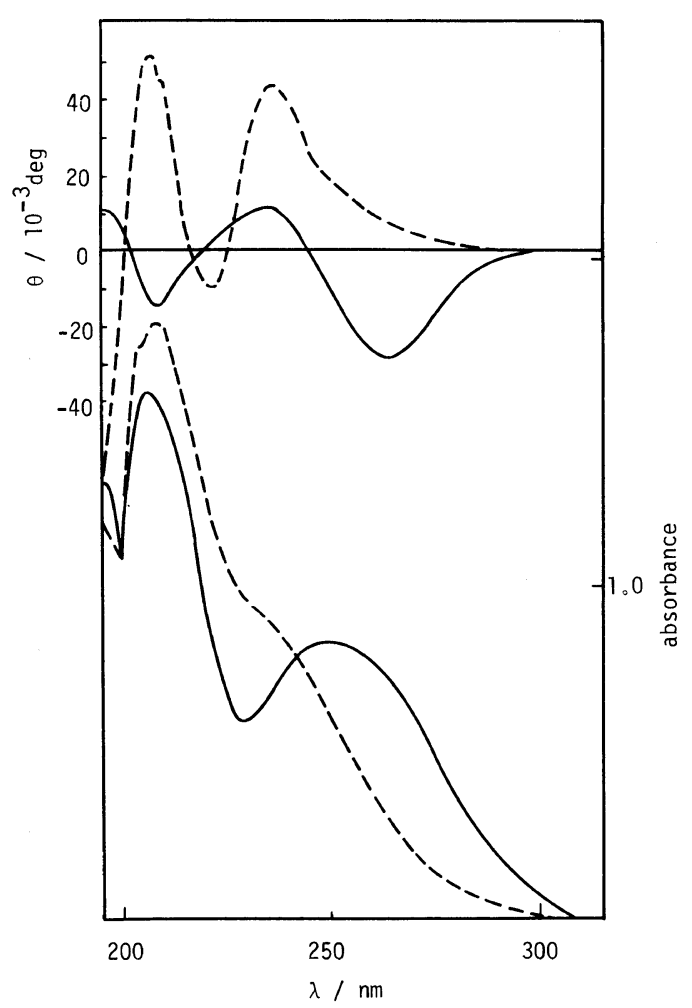

Fig. 2. CD and UV spectra of polyamide $1(-)$ and model compound $25(---)$ in film.

of the polyamides suggests that steric structure around amide bonds may be different depending on the number of the methylene units. To attain efficient chromatographic separation of optical isomers, it is preferable that the polyamides take an order structure because the efficient separation can be achieved as a result of the accumulation of a small chiral discrimination step on CSP. If the polyamides are in a disorder structure, such a regular accumulation seems to be difficult. Therefore, higher-order structure of the polyamides may play an important role for chiral recognition. In order to obtain the information on the structure, CD and UV spectra of the polyamides were measured in the solid state and in solutions. Figures 2, 3 and 4 show CD and UV spectra of polyamides 1, 2, and 14 and the corresponding model compounds $\mathbf{2 5}, \mathbf{2 6}$,

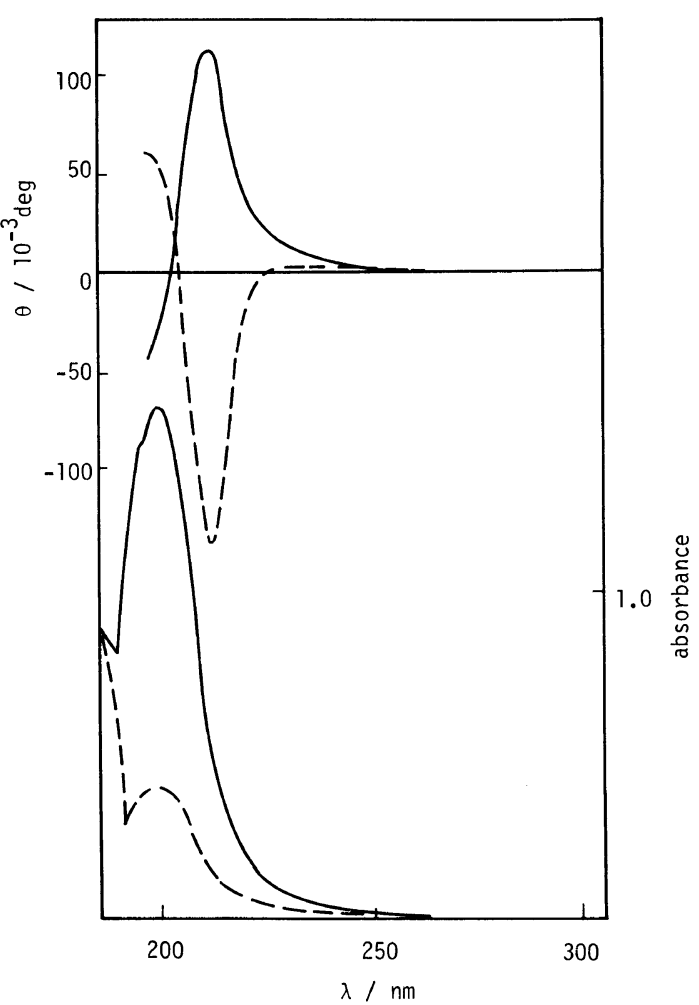

Figure 3. CD and UV spectra of polyamide $2(-)$ and model compound 26 (---) in film.

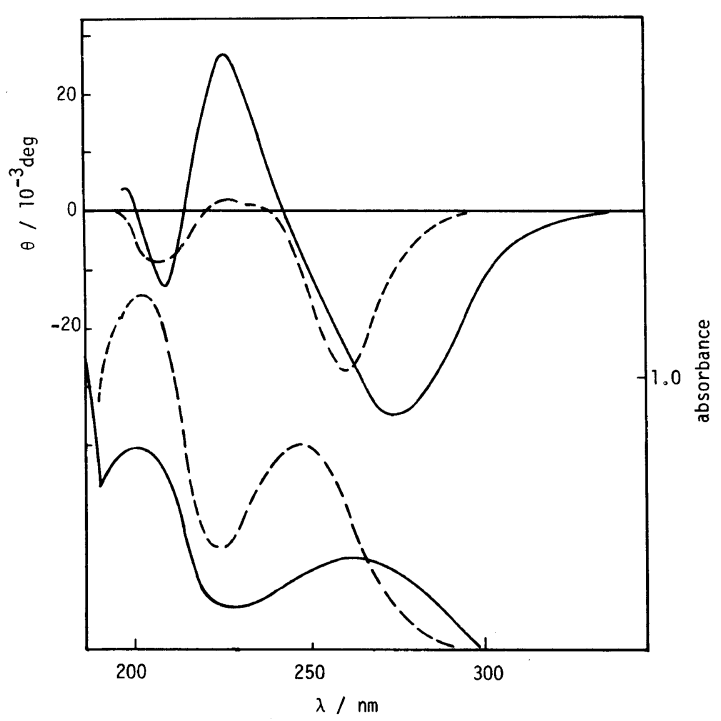

Figure 4. $\mathrm{CD}$ and UV spectra of polyamide 14 (-) and model compound 27 (---) in film. 
and 27 on solid film, respectively. The UV spectra of the films showed strong absorption assigned to the $\pi-\pi^{*}$ transition of amide chromophore at about $200 \mathrm{~nm}$. The CD spectrum of polyamide 1 showed negative peaks due to amide and aromatic chromophores at about $210 \mathrm{~nm}$ and $260 \mathrm{~nm}$, respectively (Figure 2). The $\mathrm{CD}$ spectra of polyamide 1 and corresponding model compound 25 in the solid state showed almost opposite patterns, although the CD band of phenylene group of 1 red shifted $c a .20 \mathrm{~nm}$. A positive $C D$ peak was observed at about $210 \mathrm{~nm}$ in the spectrum of polyamide 2 , and model compound $\mathbf{2 6}$ showed almost opposite CD pattern (Figure 3 ). These differences of the CD spectra between the polyamides and model compounds may be ascribed mainly to two factors, conformational factor and molecular orientation of the polyamide chain. However, the influence of the orientation of the polymer chain seems to be negligible because the

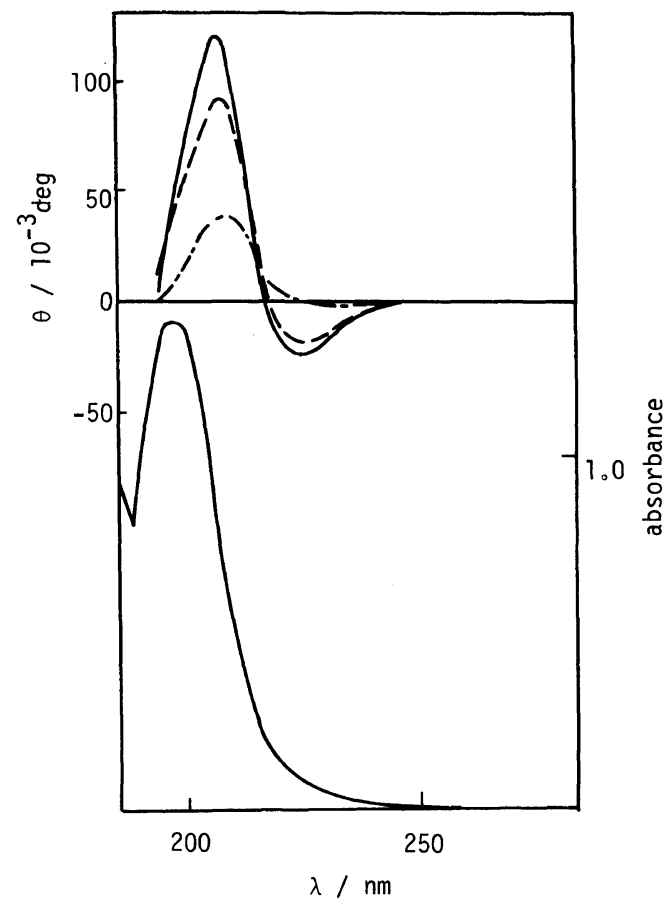

Figure 5. CD and UV spectra of polyamides $3(--\cdots)$, $5(--)$, and $7(-)$ in film. rotation of the sample in the measurement of CD spectra did not greatly varied the spectral pattern. Therefore, it is most likely that the conformation of polyamides $\mathbf{1}$ and $\mathbf{2}$ may be different from that of their corresponding model compounds. Since the solid film of the polyamides cast from a TFA solution showed high crystallinity under a polarized microscope, the polyamides seem to take regular conformation, which may result in strong interaction between the adjacent chromophores.

CD spectrum of polyamide 14 was rather similar to that of its model compound 27 (Figure 4). The polymer and model compound appear to have similar conformation in the solid state. This polyamide may not take a regular conformation. Low chiral recognition ability of polyamide 14 may be associated with the lack of regularity of the polymer chain.

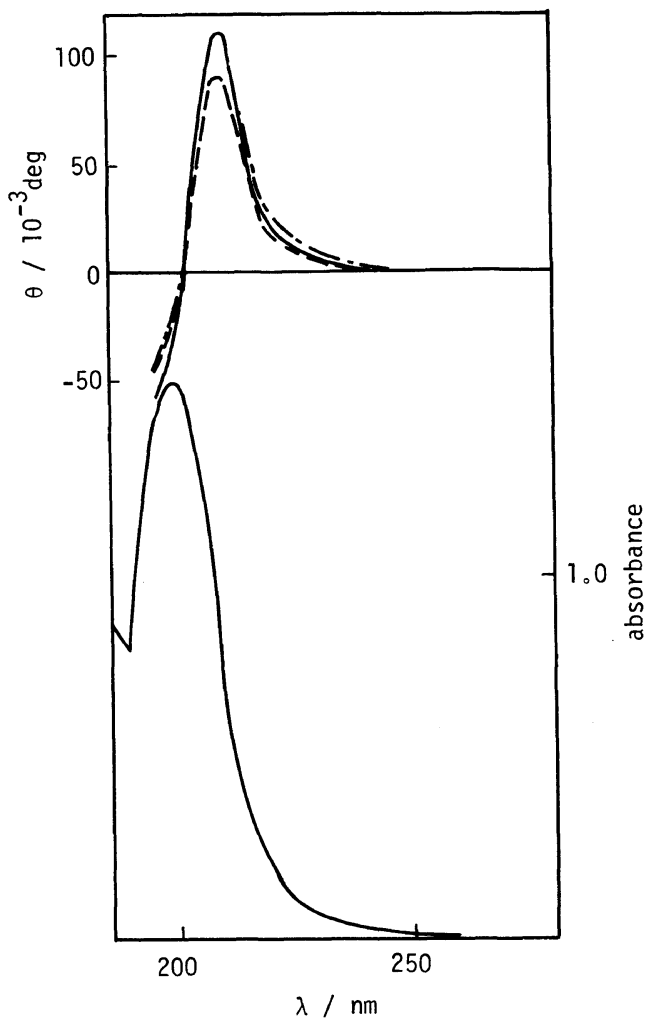

Figure 6. CD and UV spectra of polyamides 2 (----), $4(---)$, and $\mathbf{6}(-)$ in film. 


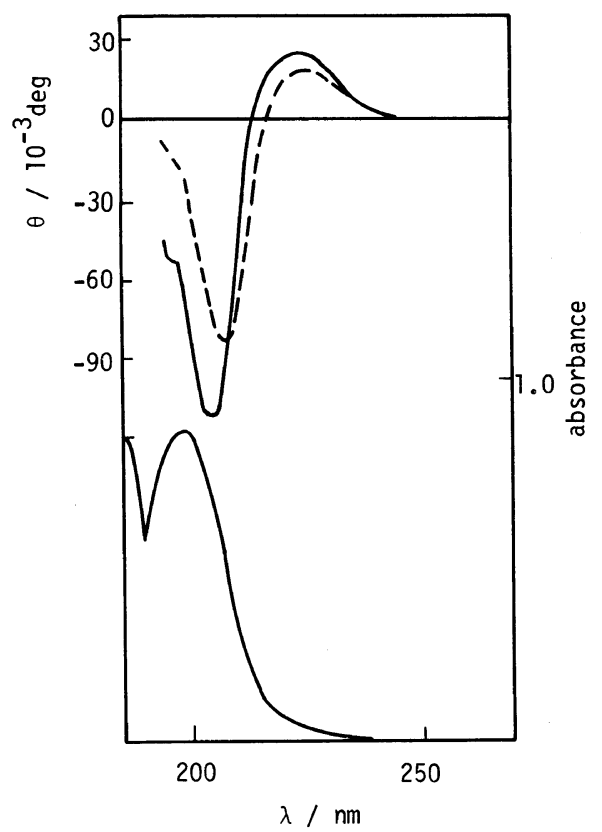

Figure 7. $\mathrm{CD}$ and UV spectra of polyamides $\mathbf{1 0}(---)$ and $12(-)$ in film.

Among polyamides 2-7 and 9-13, the CD spectra of the films of the polyamides with odd methylene units were different from those of the polyamides with even methylene units. The CD spectra of the polyamides with even methylene units derived from (-)-DA are presented in Figure 5. These spectra exhibited a weak trough at $220 \mathrm{~nm}$ probably corresponding to $n-\pi^{*}$ transition of imino chromophore in amide group. However, those of the polyamides with odd methylene units exhibited no trough (Figure 6).

On the other hand, in the polyamides derived from (+)-CDA, the polyamides having odd carbon units showed their CD band in longer wavelength region by about $10 \mathrm{~nm}$ than those of the polyamides having even carbon units (Figures 7 and 8). Odd-even effect of the number of methylene units was observed in the CD spectra. This effect may be correlated with higher-order structure of the polyamides. In solid film, polar amide groups may be associated through hydrogen bond. This

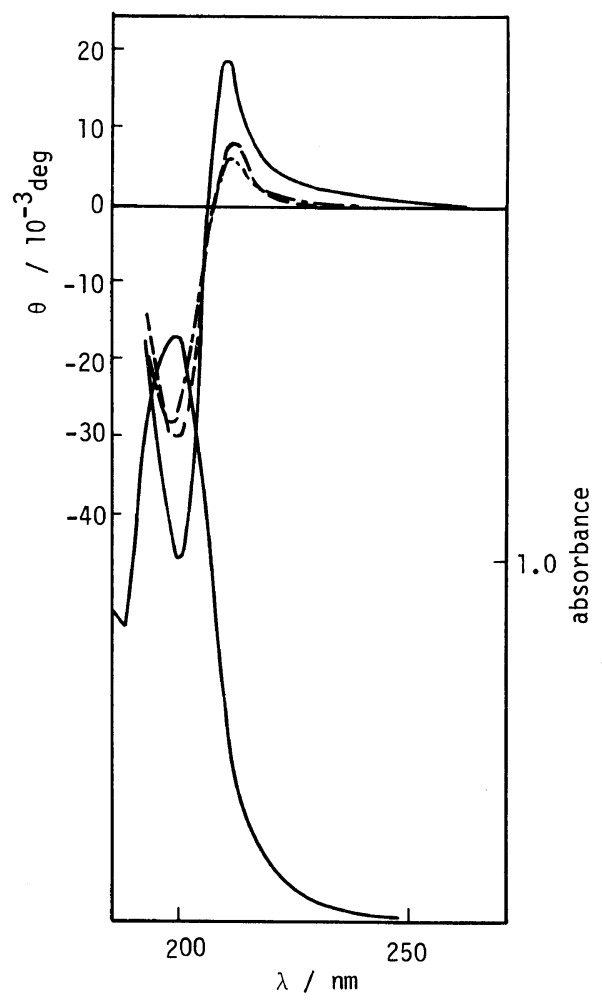

Figure 8. CD and UV spectra of polyamides $9(---), 11$ (-), and 13 (----) in film.

association may differ depending on the odd or even number of the methylene units. Saigo et al. ${ }^{9}$ showed clear odd-even effect on the optical resolving power of the polyamides derived from coumarin derivatives and $\alpha, \omega$ alkanediamines. However, in our systems such effects did not obviously appear in optical resolution although the effects were observed in CD spectra. In our systems, the small conformational difference which is observed in CD spectra may not clearly influence the chiral recognition ability of the polyamides.

\section{REFERENCES}

1. M. Zief and L. J. Crane, "Chromatographic Chiral Separation,” Marcel Dekker, New York, N.Y., 1988.

2. Y. Okamoto, CHEMTECH, 176 (1987).

3. G. Blaschke, J. Liq. Chromatogr., 9, 341 (1986).

4. Y. Saotome, T. Miyazawa, and T. Endo, Chromato- 
graphia, 28, 511 (1989).

5. Y. Okamoto and K. Hatada, J. Liq. Chromatogr., 9, 363 (1986); Y. Okamoto, H. Mohri, and K. Hatada, Polym. J., 21, 439 (1989).

6. H. Kiniwa, Y. Doi, T. Nishikaji, and N. Ogata, $J$. Chromatogr., 396, 395 (1987).

7. N. Kunieda, H. Chakihara, and M. Kinoshita, Chem. Lett., 1990, 317.

8. T. Kakuchi, T. Takaoka, and K. Yokota, Polym. J., 22, 199 (1990).

9. K. Saigo, Y. Chen, N. Yonezawa, T. Kanoe, K. Tachibana, and M. Hasegawa, Macromolecules, 19, 1552 (1986); K. Saigo, Y. Chen, K. Fujioka, N. Yonezawa, and M. Hasegawa, Chem. Lett., 647 (1988); K. Saigo, T. Shiwaku, K. Hayashi, K. Fujioka, M. Sukegawa, Y. Chen, N. Yonezawa, and M. Hasegawa, Macromolecules, 23, 2830 (1990).

10. Y. Chen, K. Saigo, N. Yonezawa, and M. Hasegawa,
Bull. Chem. Soc. Jpn., 60, 1895 (1987).

11. K. Saigo, Y. Chen, N. Kubota, K. Tachibana, N. Yonezawa, and M. Hasegawa, Chem. Lett., 515 (1986).

12. G. Montaudo, P. Finocchiaro, P. Mararigna, and C. G. Overberger, Macromolecules, 5, 197 (1972).

13. C. G. Overberger and Y. Shimokawa, Macromolecules, 4, 718 (1971).

14. C. G. Overberger and T. Nishiyama, J. Polym. Sci., Polym. Chem. Ed., 19, 331 (1981).

15. D. E. Applequist and N. D. Werner, J. Org. Chem., 28, 48 (1963).

16. C. G. Overberger, Y. Okamoto, and V. Bulacovschi, Macromolecules, 8, 31 (1975).

17. Y. Okamoto, R. Aburatani, Y. Kaida, and K. Hatada, Chem. Lett., 1125 (1988).

18. H. Koller, K.-H. Rimböck, and A. Mannschreck, J. Chromatogr., 282, 89 (1983). 